\title{
Chronic intestinal pseudo-obstruction: a diagnosis to be considered
}

\author{
M. T. Muñoz-Yagüe, P. Solís-Muñoz, I. Salces, C. Ballestín ${ }^{1}$, F. Colina ${ }^{1}$, C. Ibarrola ${ }^{1}$, G. López-Alonso ${ }^{1}$, \\ P. Carreira' ${ }^{2}$ F. Cruz Vigo ${ }^{3}$ and J. A. Solís Herruzo \\ Departments of Gastroenterology, ${ }^{1}$ Pathology, ${ }^{2}$ Rheumatology, and ${ }^{3}$ Surgery. University Hospital 12 de Octubre. Madrid, \\ Spain
}

\begin{abstract}
Chronic intestinal pseudoobstruction (CIPO) is a rare entity characterized by recurrent clinical episodes of intestinal obstruction in which no mechanical cause is identified. There are multiple causes for this syndrome but two main groups can be distinguished: a) secondary to a systemic non-gastrointestinal disease; and b) primary or idiopathic originated from alterations in the components of the intestinal wall. The latter forms are the most uncommon and their diagnosis is generally difficult. In the present article, we describe nine patients with CIPO that were diagnosed in our center over the last six years. Four of them were diagnosed with primary or idiopathic form of CIPO and another four were clearly secondary to a systemic disease. The ninth case, which was initially diagnosed as secondary, is probably also a primary form of the disease. The number of patients diagnosed in our center, even thought small, makes us to hypothesize that the prevalence of CIPO is probably greater than is generally believed and that the reasons of its rarity are the incomplete understanding of its physiopathology and the difficulties to achieve a correct diagnosis.
\end{abstract}

Key words: Diagnosis. Intestinal pseudo-obstruction. Scleroderma. Pheochromocytoma. Radiculopathy. Deficit of alpha actin.

Muñoz-Yagüe MT, Solís-Muñoz $P$, Salces I, Ballestín C, Colina F, Ibarrola C, López-Alonso G, Carreira P, Cruz Vigo F, Solís Herruzo JA. Chronic intestinal pseudo-obstruction: a diagnosis to be considered. Rev Esp Enferm Dig 2009; 101: 336-342.

Received: 16-03-09.

Accepted: 23-03-09.

Correspondence: M. T. Muñoz Yagüe. Department of Gastroenterology. University Hospital 12 de Octubre. Avenida de Córdoba, s/n. 28041 Madrid, Spain.e-mail: tmunoz.hdoc@salud.madrid.org

\section{INTRODUCTION}

CIPO is a syndrome characterized by recurrent clinical episodes of intestinal obstruction in which no mechanical cause can be identified. It is originated by a severe disturbance of the intestinal motility, in which the muscular component, the neurologic component, or both, fails to move forward the intestinal content. In some occasions, this syndrome is secondary to non-gastrointestinal diseases, but in others, it is primary or idiopathic and it is caused by intrinsic alterations of the components of the intestinal wall. The last form can be familiar or sporadic. Its clinical expression varies depending on the etiology, the localization and the extension of the disease. It is a severe and invalidating syndrome with a high morbidity. The diagnosis is difficult, particularly in the primary forms; therefore the delay to diagnosis may be long, surgical interventions are frequently indicated, and sometimes patients are classified as psychiatric. Its management represents a challenge even for reference centers with especial interest for these diseases. Treatment is oriented to improve symptoms and to maintain nutritional state. However, medical and surgical treatments are usually unsatisfactory (1-4). Classically it has been considered that this syndrome is extremely rare; in fact, the vast majority of bibliographic references is limited to case reports or small series of patients. Only in the last years, series large enough have been published to obtain valid conclusions $(5,6)$. In the present article, we describe nine patients affected by this syndrome that were diagnosed in our department in the last six years. This number, not being ours a reference center, is big enough to make us to suggest that, likely, this syndrome is more frequent than initially thought and, therefore, it must be considered in the differential diagnosis of any occlusive diseases. With that, we pretend to contribute to the earlier diagnosis of this syndrome, to a more adequate management, and to a better quality of life. 


\section{PATIENTS}

\section{Case 1}

A woman of 37 years of age (7) with constipation since childhood and episodes of fecal retention was admitted to the hospital because of abdominal pain and distention, worsening of the constipation, nausea, vomiting and loss of $15 \mathrm{~kg}$ of weight. In the plain abdominal film, small bowel loops were dilated. The rest of the studies were normal, but the isotopic study of gastric emptying and the colonic transit were pathological (Table I). Even though multiple treatments were tried, she continued to deteriorate clinically and, therefore, a colectomy with ileostomy was performed. Multiple samples from different sites of the intestinal tract were obtained. The histological study showed the presence of a myopathy not described until then (7). The immunohistological study showed a low expression of specific smooth muscle actin (1A4) in the small and large bowel. After the surgical treatment, the symptoms improved significantly and 6 years later she is clinically stable and has required hospital admissions only occasionally.

\section{Case 2}

A 29 years-old woman with chronic constipation and chronic, postprandial epigastric pain associated with great abdominal distension was attended in our service. Because of the pain, she reduced food ingestion and had lost 10 kilograms of weight. The different studies realized were normal, even the plain abdominal films. However, the isotopic studies of gastric emptying and colonic transit were abnormal (Table I). None of the treatments improved the patient's symptomatology. With the suspicion of CIPO, she was derived to a national reference center for intestinal motility disorders (Hospital Vall d'Hebron) in order to complete her study. In this center changes in intestinal motility suggested a diffuse myopathy, and transmural laparoscopic biopsies were obtained. The histological study showed an inflammatory myopathy. Treatment was prescribed (Table I) without obtaining a significant response. The symptomatology has persisted until now. Total parenteral nutrition has been indicated.

\section{Case 3}

Woman of 43 years of age with chronic constipation that had worsened progressively over time and that in the last years was associated with abdominal distention. Because of intestinal obstruction with general deterioration, three years earlier, a colectomy was done. The pathological study of the ressected sample was normal. After colectomy, important abdominal distention persisted, particularly after ingestion of food. The plain ab-

Table I. Major features of patients with chronic intestinal pseudo-obstruction syndrome

\begin{tabular}{|c|c|c|c|c|c|c|c|c|c|c|c|c|}
\hline Patient & Sex & $\begin{array}{c}\text { Age } \\
\text { (years) }\end{array}$ & $\begin{array}{c}\text { Associated } \\
\text { disease }\end{array}$ & $\begin{array}{c}\text { Proximal } \\
\text { symptoms } \\
\left(^{*}\right)\end{array}$ & $\begin{array}{c}\text { Distal } \\
\text { symptoms } \\
(* *)\end{array}$ & $\begin{array}{c}\text { Years of } \\
\text { symptoms } \\
\text { before } \\
\text { diagnosis }\end{array}$ & $\begin{array}{c}\text { Gastric } \\
\text { emptying } \\
\text { (percentage } \\
\text { at minute 30) }\end{array}$ & $\begin{array}{c}\text { Colonic } \\
\text { transit } \\
\text { (markers at } \\
\text { day } 7 \text { ) }\end{array}$ & $\begin{array}{l}\text { Obstruction } \\
\text { excluded by }\end{array}$ & Histology & $\begin{array}{l}\text { Medical } \\
\text { treatments }\end{array}$ & $\begin{array}{l}\text { Surgical } \\
\text { treatments }\end{array}$ \\
\hline 1 & $F$ & 37 & No & Yes & Yes & $9-11$ & $5 \%$ & $>50$ & $\begin{array}{l}\text { Rx, CT } \\
\text { End. }\end{array}$ & $\begin{array}{l}\text { Degenerative } \\
\text { miopathy; } \\
\text { Alpha actin } \\
\text { deficit }\end{array}$ & $P P I, P, L, O, C$ & $\begin{array}{l}\text { Colectomy } \\
\text { ileostomy }\end{array}$ \\
\hline 2 & $F$ & 29 & No & Yes & Yes & $10-12$ & $2 \%$ & $>50$ & $\begin{array}{l}\text { Rx, CT } \\
\text { End. }\end{array}$ & $\begin{array}{l}\text { Inflammatory } \\
\text { miopathy }\end{array}$ & $\begin{array}{c}P P I, P, L, O, \\
C, A B\end{array}$ & No \\
\hline 3 & $F$ & 43 & No & Yes & Yes & $9-11$ & $2 \%$ & Colectomized & $\begin{array}{l}\text { Rx , CT } \\
\text { End. }\end{array}$ & Normal & $P P I, P, A B$ & Colectomy \\
\hline 4 & $F$ & 33 & No & No & Yes & 13 & $5 \%$ & $>50$ & $\begin{array}{l}\text { Rx, CT } \\
\text { End. }\end{array}$ & $\begin{array}{l}\text { Alpha actin } \\
\text { deficit }\end{array}$ & $\begin{array}{c}P P I, P, L \\
0, A B .\end{array}$ & $\begin{array}{c}\text { Laparoscopic } \\
\text { \|leostomy }\end{array}$ \\
\hline 5 & $F$ & 59 & Scleroderma & Yes & Yes & 11 & Vomiting & No done & $\begin{array}{l}\text { Rx, CT, } \\
\text { End. }\end{array}$ & No & $P P I, P, L, A B$ & No \\
\hline 6 & $F$ & 40 & Scleroderma & Yes & Yes & 11 & - & No done & $\begin{array}{l}\text { Rx, CT, } \\
\text { End. }\end{array}$ & No & $P P I, P, L, A B$. & No \\
\hline 7 & $\mathrm{~F}$ & 45 & Scleroderma & Yes & Yes & $9-10$ & - & No done & $\mathrm{Rx}, \mathrm{CT}$ & No & $P P I, P, L, O, A B$ & No \\
\hline 8 & $\mathrm{~F}$ & 30 & Pheochromocytoma & Yes & Yes & Months & - & No done & $\mathrm{Rx}, \mathrm{CT}$ & No & $P, L$. & lleostomy \\
\hline 9 & $\mathrm{~F}$ & 51 & Radiculopathy & No & Yes & 14 & $5 \%$ & $>50$ & $\begin{array}{l}\text { Rx, CT } \\
\text { End. }\end{array}$ & No & $P P I, P, O, L$ & $\begin{array}{c}\text { Laparoscopic } \\
\text { Ileostomy }\end{array}$ \\
\hline
\end{tabular}

*Early satiety, nausea, vomiting, postprandial fullness, abdominal distension, pain; ${ }^{* *}$ Constipation, fullness, distension, pain. Rx, small bowel follow-through and barium enema; CT: computed tomography; End: endoscopy; PPI: proton pump inhibitors; P: prokynetic agents; L: laxatives; O: octeotride: C: corticosteroids; AB: antibiotics. 
dominal film showed a great dilatation of intestinal loops with ladder air fluid levels. Mechanical obstruction and other coexisting extra intestinal diseases were excluded. The isotopic gastric emptying study as well as the esophageal manometry was abnormal (Table I). With medical treatment, the patient has gained weight and her symptoms have improved but abdominal distention persists and is comparable to a 7-8 months pregnancy. She has suffered from several episodes of distention, abdominal pain, and food intolerance that required hospital admission.

\section{Case 4}

A 33-year-old woman with one delivery 14 years before as unique background. One year after labor, she began with constipation and progressive abdominal distention that worsened during the day until resembling a 9-month pregnancy. The plain abdominal film and all the rest of the diagnostic work, even the neurological evaluation, were normal and showed no abnormalities and no extraintestinal disease. Only the gastric emptying study and the colonic transit showed a delay in both studies. Administration of octreotide improved transiently the patient's symptoms. Because of the predominant colonic involvement, a palliative laparoscopic ileostomy was performed. Tissue samples were obtained from the intestinal wall and immunohistology showed a low expression of the specific smooth muscle actin (1A4) mainly in the small bowel. After the ileostomy, and even though a correct emptying of the intestinal content through the stoma was achieved, abdominal distention persisted.

\section{Case 5}

A 55-year-old woman with progressive systemic sclerosis. One year before presentation, she began with abdominal pain, regurgitation and vomiting. She had been hospitalized on several occasions because of intestinal suboclusive events. In the last months, she complained of more abdominal pain, progressive constipation and feculent vomiting. The biochemical study of the blood showed macrocitic anemia and several vitamin deficiencies. In the plain abdominal X-ray, dilatation of the small bowel and colon and air fluid levels were appreciated. The endoscopic and histological studies were normal but the esophageal manometry displayed waves of decreased amplitude. The study of gastric emptying could not be performed because of intolerance and vomiting of the preparation. The computed tomography demonstrated a marked dilatation of the small bowel with thickened wall, and symmetric and regular folds. She improved significantly with medical treatment (Table I) but continued with occasional periods of constipation or diarrhea.

\section{Case 6}

Woman of 40 years of age diagnosed with progressive systemic sclerosis 12 years earlier. One year before the diagnosis, she complained about periods of constipation alternating with others of diarrhea. Five years later, she needed hospital admission because of persistent abdominal pain, constipation, food intolerance and vomiting, followed by refractory diarrhea. She also referred dysphagia and pyrosis. The diagnostic work showed a marked reduction in the intestinal peristalsis and a delayed progression and expulsion of the contrast. The endoscopy showed esofagitis and the breath test after glucose administration was abnormal. Two years later her symptoms aggravated after the ingestion of food and she began to loose weight progressively. The plain abdominal film demonstrated distended small intestine loops and some air fluid levels. There was no response to multiple different treatments (Table I). Later on, distention appeared and the abdominal pain continued being better with decubitus and deposition but worst after meals and during periods of constipation.

\section{Case 7}

A 45 year-old women diagnosed with progressive systemic sclerosis. She complained of abdominal distention, constipation and pirosis, and had been diagnosed of gastrointestinal involvement by scleroderma. The intensity and frequency of these episodes increased with time. Vomiting and postprandial fullness appeared which obligated to decrease the ingestion of food and, consequently, she lost weight. She also did not respond to the different medical treatments (Table I). The plain abdominal film showed distended small intestine. Total parenteral nutrition has been indicated.

\section{Case 8}

A 30 year old woman, diagnosed with malignant pheochromocytoma 12 years earlier, was treated with chemotherapy and had required multiple abdominal, bone and cranial surgery. Some months before, she started with progressive constipation until being unable to defecate despite multiple treatments. She complained about abdominal pain and distention, nausea and vomiting. Weight loss appeared later in the evolution of the disease. In the plain abdominal film, air fluid levels were present but intestinal mechanical occlusion was discarded. The worsening of the symptoms made necessary to perform an ileostomy, after which the patient has improved.

\section{Case 9}

A 50 years-old woman with constipation since childhood. Her surgical antecedents were apendectomy and 
cholecystectomy. Fifteen years earlier, she had been operated on in three occasions because of lumbar disk disease. Secondary to this surgery she developed perirradicular fibrosis, neurogenic urinary bladder and residual pain that was treated in a chronic pain unit with opiates and anticholinergics. Later on, she began with episodes of progressive abdominal distention, nausea and constipation that required multiple admissions to the hospital because of intestinal suboclussion. By laparoscopy, adhesions and other causes of intestinal occlusions were excluded. The rest of the diagnostic work did not show any evidence of mechanical obstruction. The plain radiograph of the abdomen showed distended colonic and sigmoid loops as well as several air fluid levels of the small intestine. Both the isotopic study of the gastric emptying and the colonic transit time with radioopaque markers were pathological (Table I). The neurological study did not find any other alterations different from those related to the radicular affectation. The medications that aggravated her constipation were eliminated and modified. The constipation was attributed to her radicular pathology and, because of her clinical deterioration a palliative colostomy was performed. After that she remained completely asymptomatic for a year. Later on, she began with nonulcerous dyspepsia that has increased over time and that has required several hospital admissions.

\section{RESULTS (Table I)}

Between the years 2002 and 2008, we have diagnosed 9 patients that met the CIPO diagnostic criteria; that is: a) episodes of intestinal subocclusion; $b$ ) exclusion of a mechanical cause of intestinal obstruction; and c) evidence of a dilated small bowel (1-4). All of the diagnosed patients were women and had between 29 and 59 years of age (mean: 41 years). Five of them suffered from an extraintestinal condition that was responsible for the clinical syndrome. In three of them, the disease responsible was scleroderma, in one a pheochromocytoma and in another one a postsurgical radiculopathy. All of them had suffered from symptoms for more than a decade except for the patient with pheochromocytoma-related paraneoplastic syndrome. During that period of time one patient with primary or idiopathic CIPO underwent to a colectomy and another one with a secondary form underwent an exploratory diagnostic laparoscopy. Three of the primary CIPO patients had been evaluated by a psyquiatrist.

In all patients, the clinical symptoms consisted in constipation, pain and abdominal distention and seven patients, in addition to these symptoms, also suffered from postprandial fullness, nausea, and vomiting. In the primary forms, the radiological and the endoscopic studies with biopsies as well as the CT scan were normal and excluded the presence of a mechanical obstructive cause. This was also the case of patients with secondary forms not related to scleroderma. The plain abdominal film showed small bowel loop distention in two cases, air fluid level in one, and both findings in four cases. The radiography was normal in the remaining two patients. Gastric emptying isotopic study was performed in five of the patients, one with secondary and four with primary CIPO, and was abnormal in all of them (Table I). In the same patients, except in the one that had been colectomized previously, a colonic transit time with radioopaque markers was performed and was invariably pathological (Table I).

None of the four primary cases and none of the two others secondary to systemic diseases different from scleroderma responded to medical treatments (Table I). In four patients, the histological analysis of the intestinal wall was performed. In the first case, the resection piece and the samples obtained at different places of the gastrointestinal tract were analyzed. A degenerative myopathy and a deficit of alpha actin 1A4 were found (Table I). In the second, laparoscopic biopsies were obtained, which evidenced an inflammatory myopathy. In the third, the colectomy piece was studied histologically but no abnormalities were found. Lastly, in the fourth patient, the laparoscopic biopsies also showed a deficit of alpha actin.

All of the nine patients suffered from an important limitation of their quality of life and required occasionally hospitalization.

\section{DISCUSSION}

The CIPO syndrome is a clinical entity characterized by the repetition of episodes of intestinal obstruction without the demonstration of a mechanical obstructive lesion (1-4). The prevalence of this syndrome is unknown $(5,8)$. In the last six years $(2002-2008)$, we have diagnosed nine patients that met diagnostic criteria for CIPO. Not being our hospital a reference center for the treatment of motility disorders of the gastrointestinal tract, we consider that this number is enough to make us think that this syndrome has a greater prevalence than it is usually thought, and that the primary, sporadic, non familial cases of the disease are being infradiagnosed. They are nine women with ages between 29 and 59 years of age (media: 41). All of them had a history of more than ten years of evolution consisting in progressive constipation, abdominal distention and pain, and, in some cases, postprandial fullness, nausea, and vomiting. This large symptomatic period before diagnosis is in accordance with the literature $(2,5,8-10)$. The intensity of the symptoms is fluctuating but its severity usually gets worse until the first suboclussion episode occurs $(1,8,11,12)$. The disease has an important morbidity but is frequently not recognized. As a result, the patient does not receive the appropriate treatment and the severity of the disorder that he suffers is not recognized (2).

The CIPO syndrome is probably the most severe form of the neuromuscular diseases of the enteric wall, and has 
to be differentiated from other diseases of gastrointestinal motility that are much more frequent but less severe, such as recurrent abdominal pain, functional dyspepsia, irritable bowel syndrome, and cyclic vomiting. In order to differentiate the former from the remaining entities, CIPO syndrome is a severe enteric neuromuscular disease that usually needs special measures like enteral or parenteral nutrition at some point of their evolution in order to maintain an adequate nutritional state (11).

Even thought there is no consensus concerning the diagnosis of this syndrome in the adulthood, the following criteria are essential: a) episodes of intestinal subocclusion; b) demonstration of dilated small bowel; and c) exclusion of a mechanical cause of obstruction (1$4,9,13,14$ ) (Table I). All the patients described in this article met these criteria. The plain abdominal film can show signs of adynamic ileus or a dilatation of the intestinal loops similar to the one observed in mechanical obstruction (8). It has been suggested that the presence of both dilated intestinal loops with air-fluid levels, without any evidence of mechanical obstruction is an excessively restrictive criterion, since most patients with CIPO will never show any of these radiological changes at the same time. In fact, two of the four patients with primary CIPO never showed air fluid levels even though a myopathy was confirmed by histological assessment. Therefore, the diagnosis of CIPO is considered appropriate when patients present typical and severe symptoms that impair their quality of life and meet manometrical and/or histological criteria for CIPO $(8,15)$. Some authors believe that those patients with severe clinical manifestations but without radiological expression may suffer from less severe forms of the disease $(1,2)$. In our patients, mechanical obstruction was excluded by radiologic study with oral contrast, endoscopy, or tomography. The last study, like magnetic resonance imaging (MRI), is important to exclude possible causes of extrinsic intestinal compression. AngioMRI can also be used to exclude -by a non-invasive way- acquired or congenital vascular diseases (2).

When this syndrome is suspected, gastrointestinal manometry, isotopic study of the gastric emptying and histological assessment of the intestinal wall, without being completely necessary, may be very helpful in the etiological diagnosis of the syndrome, in determining the prognosis and in directing the treatment $(8,13,16,17)$. Because small bowel manometric study is not available in our center, only one of our patients underwent to this procedure. However, because of the lack of specificity, the manometric study is not essential for the diagnosis of CIPO $(1,2,14,16,18)$. The gastric emptying study with isotopes (19) was abnormal in the five patients in whom this procedure was done. In our experience, the colonic total and segmentary transit times with opaque markers were also helpful, and it was abnormal in the four patients who underwent this diagnostic procedure. The biopsies obtained by endoscopy did not provide interesting data. However, biopsies that were obtained from the whole thickness of the wall in different parts of the gastrointestinal tract or the histological assessment of the resected surgical piece allowed the study of the muscular and neural components using appropriated methods. Even though histology is considered to be the definitive test for diagnosis, its sensibility is not complete and some cases displayed normal histology. The histological assessment of the complete intestinal wall was performed in the four patients with the primary form of the syndrome, but was normal in patient number 3 who previously underwent colectomy. Because of the lack of response to the medical treatment and the predominant colonic symptomatology, a palliative ileostomy with simultaneous transmural biopsies at different levels of the intestinal tract was performed in two patients. In another patient, specimens were obtained during colectomy and, in the remaining patient, laparoscopic biopsies were obtained. In this way, the etiological diagnosis was obtained in three of the four patients with primary CIPO: one patient with degenerative myopathy and alpha actin deficiency (case 1), another with an inflammatory myopathy (case 2), and the third patient with a deficit of alpha actin (case 4). The deficient expression of alpha actin in the smooth muscle of the intestinal wall has been previously described by other authors $(20,21)$, even though its significance is not completely understood and it might be a developmental abnormality limited to the intestinal wall. For some authors (22), in absence of any structural changes, the deficiency of alpha actin is a useful indicator of primary CIPO. It is also possible that the apparent normality of the pathological assessment in selected cases may be justified by a patchy distribution of the lesions or because the existing abnormalities cannot be detected by the histochemical or immunohistological techniques used. The last option is probably the cause of the histological normality found in case 3 , since its symptoms were mainly colonic and the colon was dilated. Of the five patients in whom a palliative surgical treatment had been performed because of symptoms of colonic involvement (ileostomy in four of them and total colectomy in one), four have improved clinically in a significant manner. In case 4 , ileostomy corrected constipation but not abdominal distention even though there was no dilatation of intestinal bowel loops. Following published recommendations $(1,2)$, we tried to avoid unnecessary surgical interventions, and, when necessary, we tried to be as less aggressive as possible. Furthermore, we used surgery to obtain biopsies of the intestinal wall. This also pretends to prevent the development of adhesions that can worsen symptoms, in this case, because of a mechanical cause, and create diagnostic confusion (intestinal pseudo-pseudo-obstruction) (15).

The first four cases met criteria for primary, sporadic CIPO and they have clinical, exploratory, and progression resembling extensive involvement of the gastrointestinal tract. Three of them displayed myopathies demonstrated histologically. In the fourth case, colonic 
histology was normal, likely due to a lack of appropriate histological techniques for its diagnosis.

These patients can live for prolonged periods of time, even 30 to 40 years, if adequate nutrition is maintained and complications are adequately treated. The decrease in the mortality observed in the last years is mainly due to an improvement in the available nutritional supports $(2,18,23)$.

The three patients with CIPO secondary to scleroderma also met the diagnostic criteria for this syndrome and they have required frequent hospital admissions because of intestinal obstruction, without a mechanical cause. The symptoms they presented consisted in fluctuating periods of constipation, abdominal distention, and diarrhea; the latter because of bacterial overgrowth. They had a poor quality of life and the plain abdominal film was pathologic. Of the seven patients that we have follow because of involvement of the gastrointestinal tract only three met CIPO criteria. Likely, they are also the ones in the most advanced stages of the disease. Because of this, it is also possible that, in the near future, we will find more patients with scleroderma complicated with CIPO syndrome, since survival of these patients is increasing. In these cases, the etiological diagnosis is not difficult as gastrointestinal involvement is found in $80 \%$ of the cases patients with scleroderma. Even though any part of the digestive tract can be affected, esophageal involvement is the most common (24-27). When we began their study because of the suspicion of CIPO, their esophageal symptoms were already controlled with high dose proton pump inhibitors. It is also known that gastrointestinal involvement can be improved with treatment of the primary disease, particularly in the early stages of the disease, when neuromuscular disorganization of the wall has not occurred $(2,28)$. In the patient with paraneoplastic CIPO, other causes were also excluded. It is a rare complication of malignant pheochromocytoma that is attributed to the prolonged effect of catecholamines on the intestinal motility (29-31). The diagnostic challenge was greater in patient number nine. This patient also met all CIPO criteria, but the only relevant medical antecedents were several surgical interventions on the lumbar spine. Therefore, it was interpreted that a periradicular fibrosis was the cause of this syndrome. Since a diverting ileostomy solved initially her problems, a primary form of CIPO cannot be excluded.

We conclude that CIPO is probably more frequent than usually thought and that, in numerous cases, this syndrome is not diagnosed because it is not considered in the differential diagnosis. Its diagnosis is difficult because of the lack of a reliable biological marker of disease and because of clinical overlapping with severe forms of other gastrointestinal syndromes. Management of these patients constitutes a challenge even for specialized reference centers. The nutritional state must be carefully maintained, complications must be treated as they appear, the number of surgical interventions must be minimized and transmural biopsies must be obtained earlier in the course of the disease when the syndrome can still respond to therapy. We pretend to call attention upon this entity, because early diagnosis can improve management of these patients and improve their quality of life.

\section{REFERENCES}

1. Antonucci A, Fronzoni L, Cogliandro L, Cogliandro RF, Caputo C, De Giorgio R, et al. Chronic intestinal pseudo-obstruction. World J Gastroenterol 2008; 14: 2953-61.

2. Stanghellini V, Cogliandro RF, De Giorgio R, Barbara G, Salvioli B, Corinaldesi R. Chronic intestinal pseudo-obstruction: manifestations, natural history and management. Neurogastroenterol Motil 2007; 19: 440-52.

3. Cogliandro RF, De Giorgio R, Barbara G, Cogliandro L, Concordia A, Corinaldesi R, et al. Chronic intestinal pseudo-obstruction. Best Pract Res Clin Gastroenterol 2007; 21: 657-69.

4. Muñoz MT, Solís-Herruzo JA. Pseudo-obstruction intestinal crónica. Rev Esp Enferm Dig 2007; 99: 100-11.

5. Stanghellini V, Cogliandro RF, De Giorgio R, Barbara G, MorselliLabate AM, Cogliandro L, et al. Natural history of chronic idiopatic intestinal pseudo-obstruction in adults: a single center study. Clin Gastroenterol Hepatol 2005; 3: 449-58.

6. Mann SD, Debinski HS, Kamm MA. Clinical characteristics of chronic idiopathic intestinal pseudo-obstruction in adults. Gut 1997; 41: 675-81.

7. Muñoz-Yagüe MT, Marín JC, Colina F, Ibarrola C, López-Alonso G, Martín MA, et al. Pseudo-obstrucción intestinal crónica primaria debida a miopatía visceral. Rev Esp Enferm Dig 2006; 98: 292-302.

8. Di Lorenzo C. Pseudo-obstruction: Current aproaches. Gastroenterology 1999; 116: 980-7.

9. De Giorgio R, Sarnelli G, Corinaldesi R, Stanghellini V. Advances in our understanding of the pathology of chronic intestinal pseudo-obstruction. Gut 2004; 53: 1549-52.

10. Keller J, Layer P. Chronic intestinal pseudo-obstruction: pathogenesis, diagnosis and therapy. Z Gastroenterol 2002; 40: 85-95.

11. Cucchiara S. Chronic intestinal pseudo-obstruction: The clinical perspective. J Pediatr Gastroenterol Nutr 2001 (Supl. I): S21-22.

12. Kamm MA. Intestinal pseudo-obstruction. Gut 2000; (Supl. IV): $47 i v 84$.

13. Panganamula KV, Parkman HP. Chronic intestinal pseudo-obstruction. Curr Treat Options. Gastroenterol 2005; 8: 3-11.

14. Sutton DH, Harrel SP, Wo JM. Diagnosis and management of adults patients with chronic intestinal pseudo-obstruction. Nut Clin Prac 2006; 21: 16-22.

15. Silk DBA. Pseudo-pseudo obstruction: lessons in diagnosis and management. Eur J Gastroenterol Hepatol 2004; 16: 959-60.

16. Cogliandro R, Stanghellini V, Cogliandro L. Small bowel manometric findings in different forms of severe digestive syndromes. Neurogastroenterol Motil 2004; 16: A838.

17. Connor FL, Di Lorenzo C. Chronic intestinal pseudo-obstruction: Assessment and management. Gastroenterology 2006; 130(2Supl.1): S29-36.

18. Schuffler MD. Chronic intestinal pseudo-obstruction. In: Feldman M, Friedman LS, Sleisenger MH, editors. Sleisenger \& Fordtran's. Gastrointestinal and Liver diseases. 7th ed. Philadelphia: Saunders; 2002. p. 2140-50.

19. Tougas G, Eaker EY, Abell TL, Abrahamsson H, Boivin M, Chen J, et al. Assessment of gastric emptying using a low fat meal: establishment of internal control values. Am J Gastroenterol 2000; 95: 145662.

20. Smith VV, Milla PJ. Histological phenotypes of enteric smoth muscle disease causing functional intestinal obstruction in childhood. Histopathology 1997; 31: 112-22.

21. Smith VV, Lake BD, Kamm MA, Nichols JR. Intestinal pseudo-obstruction with deficient smoth muscle alfa actin. Histopathology 1992; 21: 535-42. 
22. Knowles CH, Silk DB, Darzi A, Veress B, Feakins R, Raimundo AH, et al. Deranged smooth muscle alfa-actin as a biomarker of intestinal pseudo-obstruction: a controlled multinational case series. Gut 2004; 53: 1583-9.

23. Moreno Villares JM. Pseudo-obstrucción intestinal crónica primaria debida a miopatía visceral. Rev Esp Enferm Dig 2006; 98: 705-6.

24. Domsic R, Fasanella K, Bielefeldt K. Gastrointestinal manifestations of systemic sclerosis. Dig Dis Sci 2008; 53: 1163-74.

25. Takahashi H, Ohara M, Imai K. Collagen diseases with gastrointestinal manifestations. Nihon Rinsho Meneki Gakkai Kaishi 2004; 27 : 145-55.

26. Marie I. Gastrointestinal involvement in systemic sclerosis. Press Med 2006; 35(12Pt2): 1952-65.

27. Attar A. Digestive manifestations in systemic sclerosis. Ann Med In- terne (Paris) 2002; 153: 260-4

28. Stanghellini V, Corinaldesi R, Ghidine C, Ricci Maccarini M, De Giorgio R, Biasco G, et al. Reversibility of gastrointestinal motor abnormalities in chronic intestinal pseudo-obstruction. Hepatogastroenterology 1992; 39: 34-8

29. Khafagi FA, Lloyd HM, Gough IR. Intestinal pseudo-obstruction in pheochromocytoma. Aust N Z J Med 1987; 17: 246-8.

30. Murakami S, Okushiba S, Ohno K, Ito K, Satou K, Sugiura H, et al. Malignant fheochromocytoma associated with pseudo-obstruction of the colon. J Gastroenterol 2003; 38: 175-80.

31. Mullen JP, Cartwright RC, Tisherman SE, Misage JR, Shapiro AP. Pathogenesis and pharmacologic management of pseudo-obstruction of the bowel in pheochromocytoma. Am J Med Sci 1985; 290: $155-8$. 